\title{
Study of the conservation and exhibition of burned wall paintings in the main hall of the treasure house at Horyu-ji Temple
}

\author{
Takuya Wada ${ }^{1, *}$, Daisuke Ogura ${ }^{1}$, Chie Sano $^{2}$, Shuichi Hokoi ${ }^{1}$, Chiemi Iba $^{1}$ \\ ${ }^{1}$ Graduate School of Engineering, Kyoto University \\ ${ }^{2}$ Tokyo National Research Institute for Cultural Properties
}

\begin{abstract}
Horyu-ji Temple is the main temple and Buddhist monument in the Horyu-ji area designated a UNESCO world heritage site since 1993. In 1949, the main hall in the Horyu-ji Temple, Nara prefecture, Japan, suffered a fire. Paintings on the burned walls are now stored with other cultural property in the treasure house which has no air conditioning, and doors and windows that are always closed. There is a fear of mold and pest generation due to high relative humidity in the room, so the environment must be controlled to protect the wall paintings from biological damage. Furthermore, Horyu-ji is considering an exhibition of the burned wall paintings in the treasure house, and we therefore need to consider the impact of visitors' heat and moisture on the generation of mold and pests on the wall. I investigated environmental control methods using a blower in the attic space by numerical analysis. The analysis was performed in two case scenarios. One case involved preserving the walls in a closed treasure house and the other supposed an exhibition. As a result of this analysis, the effect of the reduction of relative humidity using a blower was clarified quantitatively.
\end{abstract}

\section{Introduction}

In 1949, Horyuji Kondo (the main hall in Horyu-ji Temple) suffered a fire, and a lot of wall paintings were burned. After the fire, the treasure house where the burned wall paintings, burned pillars, and other cultural properties were preserved was built. At present, the treasure house is not open to the public and there is no air conditioning equipment, but we are considering opening it in the future. There is a fear of mold and pest generation on the walls [1], and we need to find a method to control the temperature and humidity to improve the preservation environment. Borostrom et.al[9] and Wessberg[10] clarified that an adaptive ventilation method is efficient to lower relative humidity in historic buildings. Borostrom et.al has shown that the adaptive ventilation had a significant drying effect removing water in historic buildings. Wessberg[10] investigated effect of the adaptive ventilation using a mold risk assessment. However, there are no studies on how to adjust the environment by dehumidifying the space using the attic space air. The purpose of this study is to propose architectural countermeasures and environmental control methods to prevent damage to cultural property by mold and pests. In this report, we consider dehumidification by operating a ventilation blower in the attic space and ceiling in the treasure house, which tends to be very humid. Our investigation used the thermo-moisture analysis model of the storehouse from a previous report [2]. This research was conducted as part of a survey by the Preservation Environment Working Group under the

\footnotetext{
* Corresponding: twada80053562@gmail.com
}

Horyuji Kondo Mural Preservation and Utilization Committee.

\section{Results of field measurements}

\subsection{Building description}

The central storeroom houses the burned wall paintings, and on the east, west and north side of the central room, there are rooms which store wood and other materials. In addition, there are two second floor rooms on the east and west sides. The second floor of the central room is an atrium corridor with a ceiling height of two floors, and each room has an attic space at the top. There is a door between each attic space, and the west attic has a vent to the outside. Between attic spaces and rooms, there are also ceiling openings. The building is made of reinforced concrete and the painted wall is made of wood and soil.

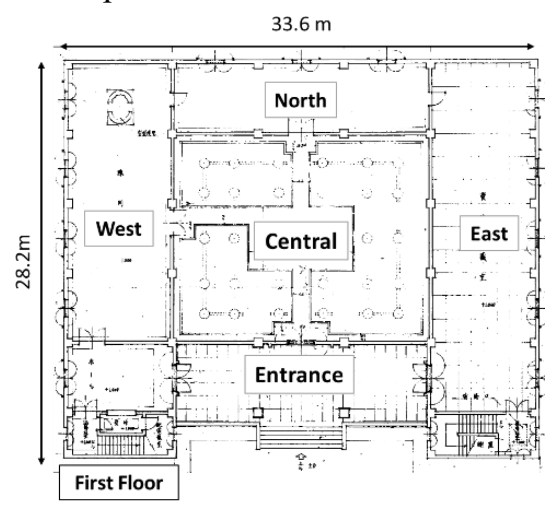

Fig. 1. 1st floor plan 


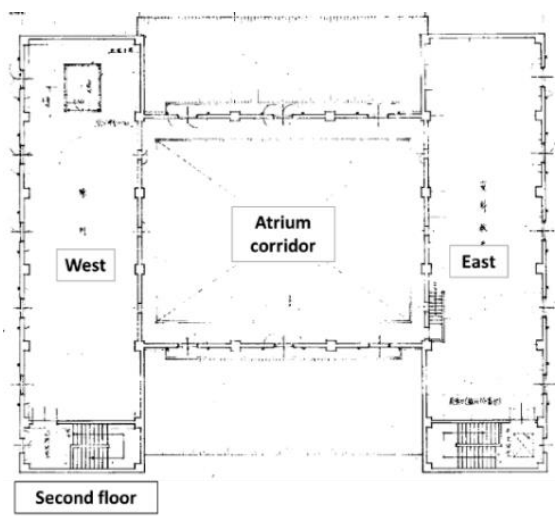

Fig. 2. 2nd floor plan

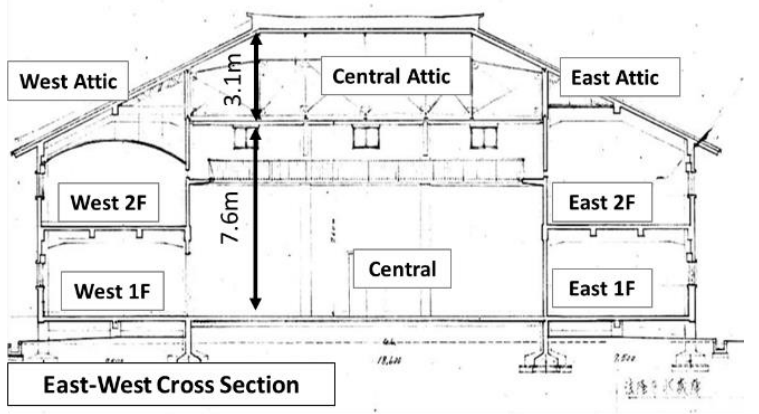

Fig. 3. Cross section plan

\subsection{Measurement results}

Figs. 4, 5, and 6 show temperature, absolute humidity, and relative humidity measurements in each room for one year from December 7, 2017. The storeroom temperatures on the first floor were stable and about $2{ }^{\circ} \mathrm{C}$ higher than outside throughout the year. Relative humidity fluctuates between $55 \%$ and $70 \%$ and tends to increase in summer. The reason the fluctuation width is small is that the ventilation rate is small, and the walls and the stored materials absorb and desorb moisture which maintains the rooms' relative humidity.

\section{Humid environments suppress the deterioration of cultural property caused by living things}

To prevent the growth of mold and pests among cultural property, control of the room environment can be performed from two aspects: temperature and humidity. However, since the temperature at which mold and pest are not active is intolerable even to humans, we will consider controlling humidity.

Relative humidity should be maintained between $50 \%$ to $60 \%$ [3] to prevent the growth of mold and pests in storage. If the relative humidity is higher than this, the risk of mold generation increases [4] because an environment with a relative humidity of $75 \%$ [5] causes cultural property pests to become very active. Moreover, a large fluctuation in humidity could cause the exfoliation of the paintings' surface. Therefore, maintaining a constant and low humidity state is desirable. This study aimed to realize a stable relatively humid environment of $50 \%$ to
$60 \%$ that suppresses the biological deterioration of cultural property in the storeroom.

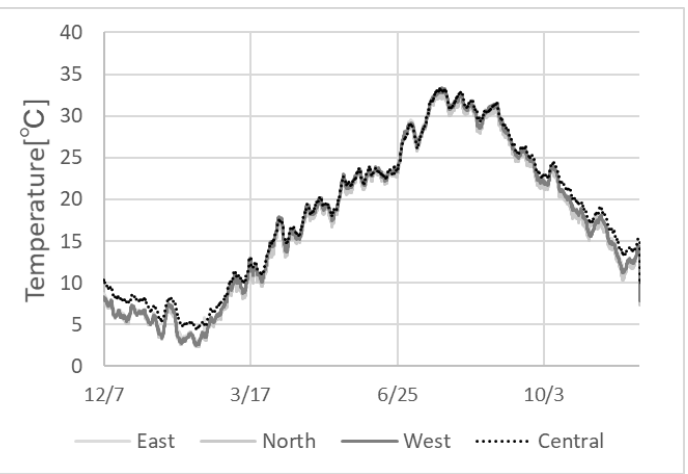

Fig. 4. Temperature of each room on the 1 st floor

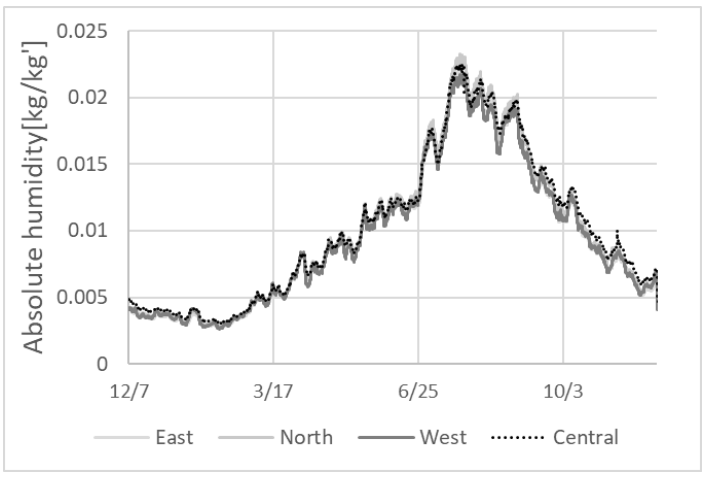

Fig. 5. Absolute humidity of each room on the 1st floor

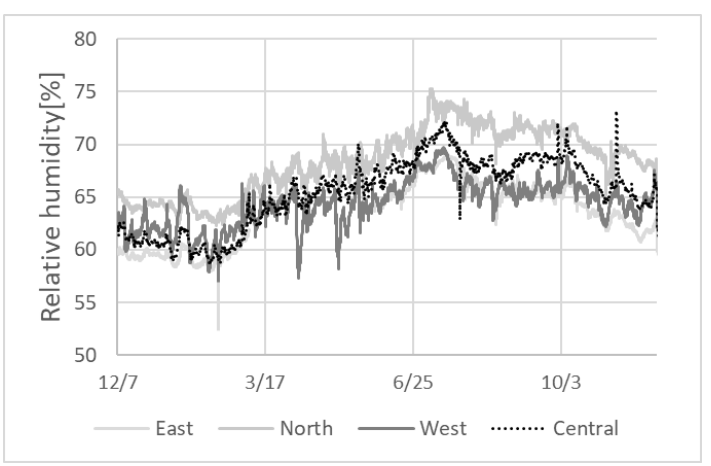

Fig. 6. Relative humidity of each room on the 1st floor

\section{Hygrothermal analysis model}

\subsection{Basic equation}

As in the previous report [2], the treasure house model is composed of ten rooms, and the walls and floors were modeled in one dimension in the analysis. The materials' heat and moisture transfer values were based on coupled heat and moisture transfer equations [6] using temperature and water chemical potential as driving forces. The temperature and humidity of the room were obtained from the following heat and moisture balance equations for a single degree of freedom system. Moisture and heat equations were separately expressed as Eqs. (1) and (2), respectively:[7] 


$$
\begin{gathered}
\rho V_{r} \frac{\partial X}{\partial t}=\sum_{i=1}^{I} \alpha_{X}^{\prime} S_{i}\left(X_{b i}-X\right)+\sum_{j=1}^{J} G_{j} X_{u p r}-\sum_{k=1}^{K} G_{k} X+W_{g e n} \\
c \rho V_{r} \frac{\partial T}{\partial t}=\sum_{i=1}^{N} \alpha_{r} S_{i}\left(T_{b i}-T\right)+c\left(\sum_{j=1}^{J} G_{j} T_{u p r}-\sum_{k=1}^{K} G_{k} T\right)+Q_{g e n}+Q_{w n d}
\end{gathered}
$$

$t \quad:$ time [s]

$T \quad$ : temperature [K]

$c \quad$ : specific heat $[\mathrm{J} / \mathrm{kg} \cdot \mathrm{K}]$

$\rho \quad:$ air density $\left[\mathrm{kg} / \mathrm{m}^{3}\right]$

$V_{r} \quad$ : room volume $\left[\mathrm{m}^{3}\right]$

$\alpha_{x}$ ' : surface moisture transfer coefficient $\left[\mathrm{kg} / \mathrm{m}^{2} \mathrm{~s}\left(\mathrm{~kg} / \mathrm{kg}^{\prime}\right)\right]$

$S i \quad$ : area of i-th wall $\left[\mathrm{m}^{2}\right]$

$X_{b i} \quad$ : absolute humidity of $\mathrm{i}$-th wall surface $\left[\mathrm{kg} / \mathrm{kg}^{\prime}\right]$

Gj : inflow rate of $\mathrm{j}$-th opening $\left[\mathrm{kg} / \mathrm{m}^{3}\right]$

$X_{\text {upr }}$ : absolute humidity of other rooms $\left[\mathrm{kg} / \mathrm{kg}^{\prime}\right]$

$G_{j} \quad$ : outflow rate of k-th opening $\left[\mathrm{kg} / \mathrm{m}^{3}\right]$

$W:$ moisture generation rate $[\mathrm{kg} / \mathrm{s}]$

$\alpha_{r}$ : surface heat transfer coefficient $\left[\mathrm{W} / \mathrm{m}^{2} \mathrm{~K}\right]$

$T_{b i} \quad:$ temperature of surface $[\mathrm{K}]$

$T_{u p r}:$ temperature of other rooms [K]

$Q_{\text {gen }}:$ heat generation rate [W]

$Q_{\text {wnd }}$ : heat flux of windows [W]

\subsection{Outline of the analysis model}

In the analytical model, solar radiation and effective radiation were considered. The model using each wall structure and each physical property refer to the previous report [2]. The ventilation volume of the opening between the rooms was determined by a ventilation network analysis using the pressure assumption method [8]. Ventilation considers only temperature difference, the external wind is not considered. The values identified in the previous report [2] were used to determine the opening conditions.

\subsection{Validity of the simulation}

Figs. 7 and 8 show a compare the measured and calculated distributions of temperature and humidity ratios. The outside temperature here is the daily average. The results calculated agreed fairly well with the experimental measurements in the room throughout the year.

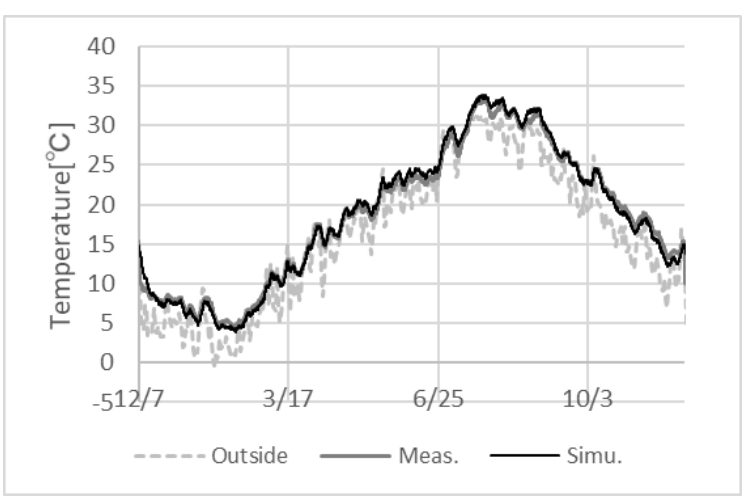

Fig. 7. Temperature of the central storeroom

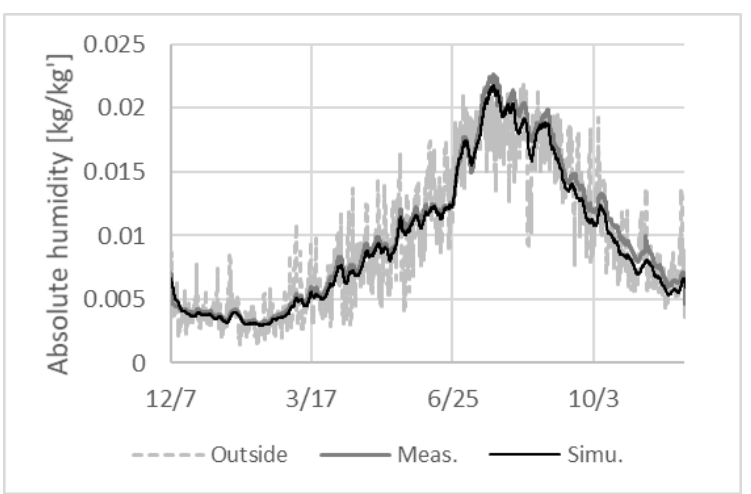

Fig. 8. Absolute humidity of the central store room

\section{Consideration of environmental adjustment methods during closure}

\subsection{The conditions for an environmental control method using a ventilation fan}

\subsubsection{Temperature and humidity of the attic space}

Figs. 9, 10, and 11 show the temperature, absolute humidity, and relative humidity measurements in the central storeroom, in the central attic space, and of the outside air. In the attic space, the daily fluctuation in temperature and absolute humidity was large. The attic space's fluctuation in temperature was due to the temperature fluctuation in the roof caused by the absorption of solar radiation. The temperature fluctuation in the roof also causes moisture absorption and desorption in the roof causing a large daily fluctuation in absolute humidity.

\subsubsection{Ventilation conditions used for calculation}

Using the analysis model, we considered using ventilation fans in the attic space air to dehumidify the central storeroom. If a ventilation fan is installed in the opening of the west attic space, air will be drawn out from the storeroom through the ceiling opening and the door between the west and central attic space. Outside air will be supplied to the storeroom from the gaps in the doors and windows. If a fan is installed in the ceiling opening and the fan in the west attic space is not operating, the air in the storeroom is supplied to the central attic space, and the air in the attic returns to the storeroom through another ceiling opening. The calculation was performed by considering the above fan functions. Fig. 13 shows a schematic diagram of ventilation methods under each calculation condition. The arrows in the figure indicate the position of the fan and the blowing direction. Circles indicate rooms with absolute humidity to compare. The fans operate when the absolute humidity of the light circled space is higher than that of the dark circled space. CASE0 is a calculation that reproduces the current store house's temperature and humidity without ventilation fans. CASE1 to 3 are calculations that consider fan installation and operating conditions. Table 1 shows the absolute humidity conditions at which the fan operates. In CASE1 to 3 , the air volume of the fan was set to $648 \mathrm{~m}^{3} / \mathrm{h}$ 
for both the roof and the ceiling. In addition, to draw the air from the central attic space to the west attic space, it was assumed that the ceiling openings of the second floor of the west room were closed.

Table 1. Condition of ventilation fan operating

\begin{tabular}{|c|c|c|c|}
\hline Fan & attic opening & ceiling & \\
\hline CASE0 & NO & NO & {$\left[\mathrm{kg} / \mathrm{kg}^{\prime}\right]$} \\
\hline CASE1 & $X_{0}<X_{c a}$ & NO & o: outsi \\
\hline CASE2 & $X_{0}<X_{c r}$ & NO & ca: central att \\
\hline CASE3 & $X_{0}<X_{c a}, X_{c r}$ & Xca $<$ Xcr & cr: central storero \\
\hline
\end{tabular}

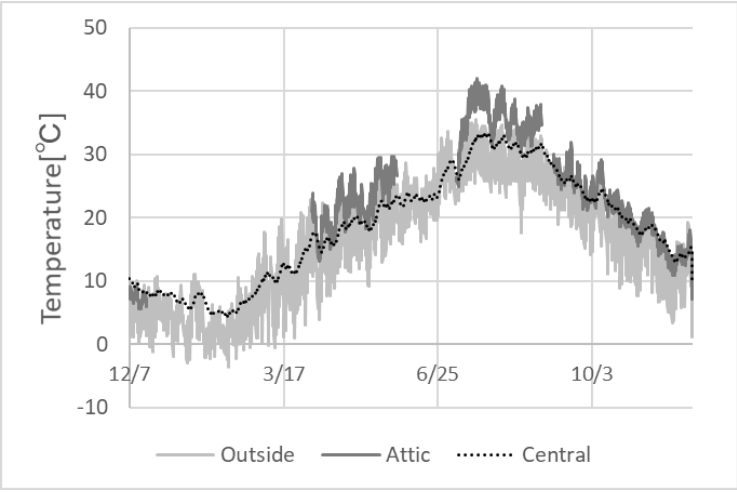

Fig. 9. Temperature of the storeroom and the attic space

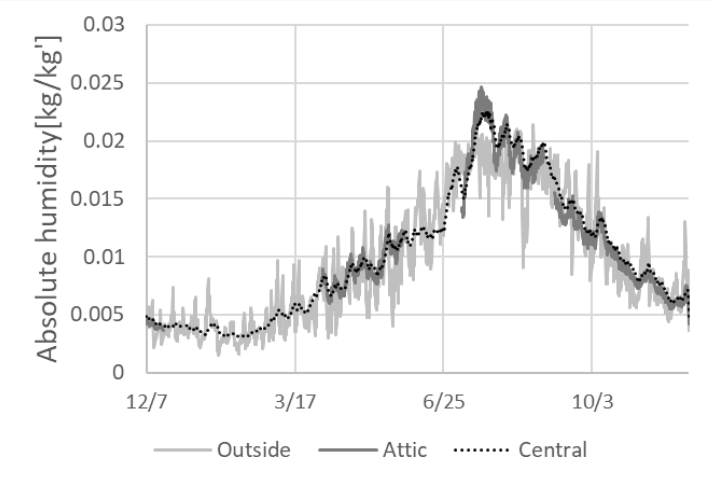

Fig. 10. Absolute humidity of the storeroom and the attic space

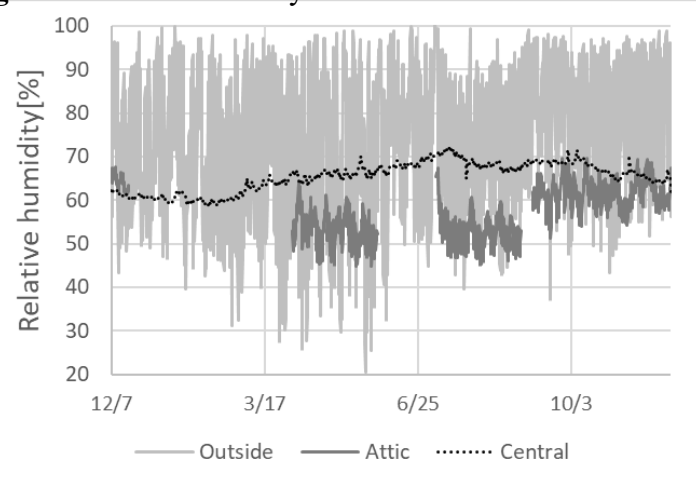

Fig.11 : Relative humidity of the storeroom and the attic space

\subsection{Calculation results and discussion}

Fig. 12 compares relative humidity with different ventilation methods. A comparison of the temperature in each case is not shown because the differences in temperature in all cases were small. Absolute humidity decreased in each case. The relative humidity of CASE1 to 3 which included ventilation with a fan, decreased compared to CASE0 which had no fan ventilation, but the fluctuation became slightly larger. Relative humidity decreased in the order of CASE1, CASE2, CASE3 throughout the year. CASE1 uses a ventilation method that ensures the amount of water vapor discharged from the entire storehouse is positive, and CASE2 uses a ventilation method that ensures the amount of water vapor discharged from the central storeroom is positive. Storeroom humidity reduced more in CASE2 than CASE1. In CASE3, when the absolute humidity of the central attic space is lower than that of the central storeroom, both rooms' air mix and as a result, relative humidity is further reduced compared to CASE1. When humidity is controlled by taking in outside air with a fan, the average relative humidity of the storeroom would be reduced but its fluctuation would become slightly larger.

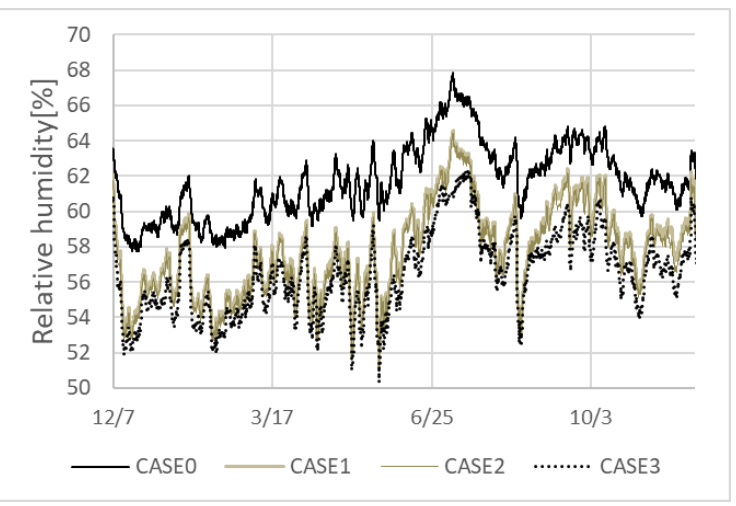

Fig. 12. Relative humidity of the storeroom in ventilation case

\section{Environmental control considering visitors during winter}

In the previous section, we found that the ventilation method of CASE 3 would be the most effective at reducing relative humidity. Using method CASE 3, we will consider the environmental control method most suited when visitors attend at the time of opening. The storehouse opens during the winter period (Jan.1-Jan.31). In winter the temperature is low; therefore, the cultural property pests are not active, and the risk of pest generation on the wall is small. The amount of heat and moisture generated by a human body was determined from reference [11]. The total amount of heat is $91[\mathrm{~W} /$ person] and the amount of water generated is calculated by dividing the amount of latent heat by the latent heat of vaporization. $\left(1.08 \times 10^{-5}[\mathrm{~kg} / \mathrm{s} \cdot\right.$ person] $)$ Opening time is between 8:00 and 16:00, and it was assumed that ten people were always in the central storeroom and the first floor of the west room.

\subsection{Opening and fan conditions}

During each visit, it was assumed that the south door of the storage room at the south side would be open from 8:00 to 16:00. In addition, it was assumed that the door between the central storeroom and the first floor of the 
west room would always be open in all calculations in order to ventilate the first floor of the west room. In CASE3-0, no window is opened. In CASE3-1, one of the windows on the first floor of the west room is opened from 7:00 to 17:00. In CASE3-2 the same window on the first floor of the west room is open when the absolute humidity of the first floor of the west room is higher than that outside. In this case, the window is automatically opened and closed. CASE3-3 is the case where the air volume of the ceiling/roof fan is doubled, and other conditions are the same as CASE3-2. CASE0E is the case only assuming entry to the room without installing a fan or opening/closing windows.

Table 2. West room's window and ventilation volume conditions

\begin{tabular}{|l|l|l|}
\hline & window opening & vent volume \\
\hline CASE0E & NO & NO \\
\hline CASE3-0 & NO & $\mathrm{x} 1$ \\
\hline CASE3-1 & $7: 00-17: 00$ & $\mathrm{x} 1$ \\
\hline CASE3-2 & $\mathrm{X}_{0}<\mathrm{X}_{w r}$ & $\mathrm{x} 1$ \\
\hline CASE3-3 & $\mathrm{X}_{0}<\mathrm{X}_{w r}$ & $\mathrm{x} 2$ \\
\hline
\end{tabular}

wr: the first floor of west room
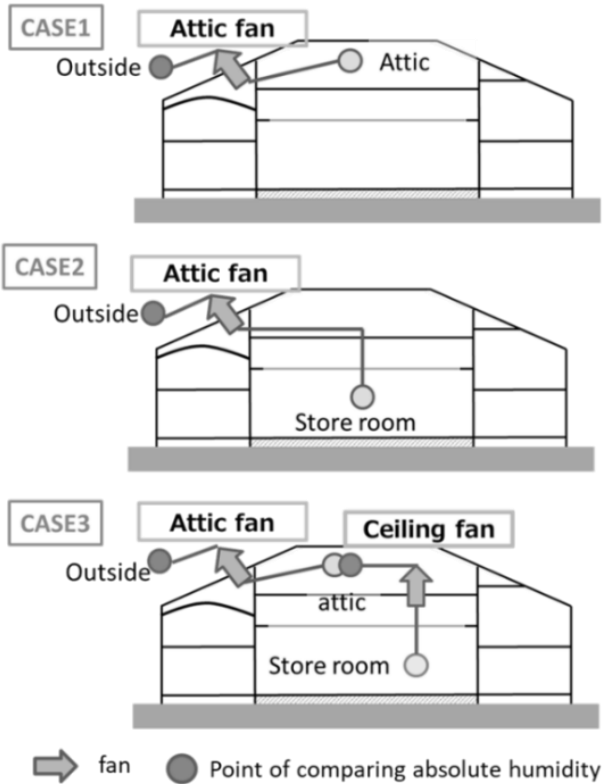

Fig. 13. Ventilation method in each csae

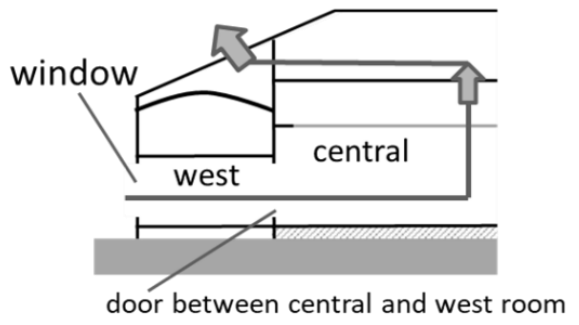

Fig. 14. Ventilation route when the window is open

\subsection{Calculation results and discussion}

Figs. 15 to 17 show the results of temperature, absolute humidity, and relative humidity calculations in the storeroom. As shown in the figure, the relative humidity is reduced by all ventilation methods except for CASE31 , compared to the case with no ventilation (CASE0E). In CASE3-1, whether a window is open or closed depends on the time and moisture of the outside flow into the room. The relative humidity in each room is lowered by 2 to $4 \%$ when the CASE 3 ventilation method is used.

In addition, in CASE3-2, 3-3, which included conditions for opening and closing windows, the relative humidity can be further reduced. In CASE3-3, the fan air volume is doubled from CASE3-2 but the relative humidity is little further reduced. In figure 16 depicting the impact of outside air on absolute humidity, whether the room can be dehumidified depends on the outside air absolute humidity but fluctuates greatly. It is difficult to maintain a low and stable relative humidity in the storeroom using outside air. If the room is always open and people enter continuously, the relative humidity may increase temporarily.

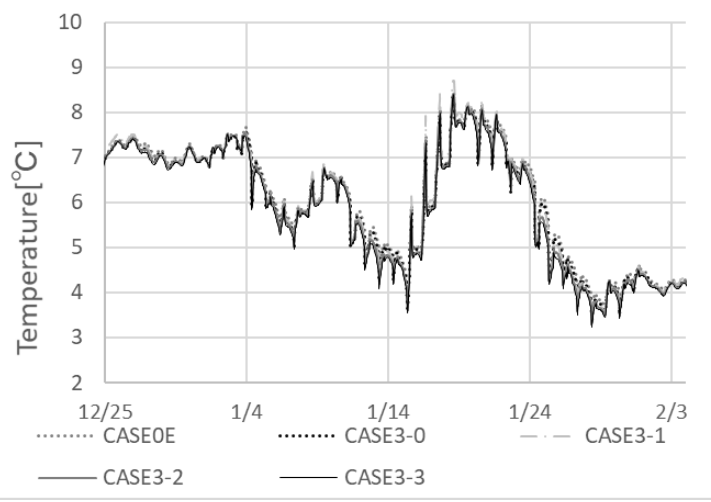

Fig. 15. Temperature of the central room during opening

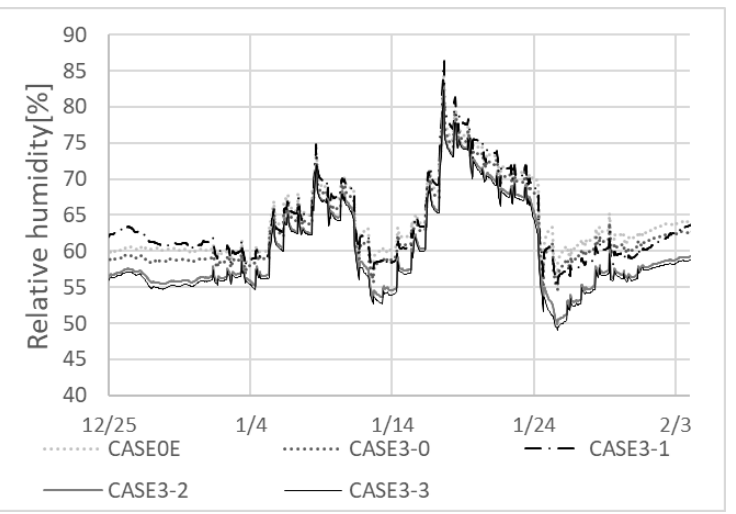

Fig. 16. Absolute humidity of the central room during opening

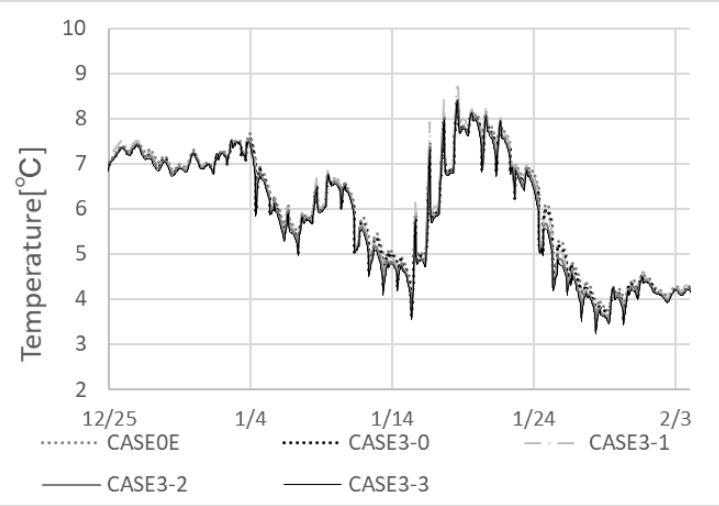

Fig. 17. Relative humidity of the central room during opening 


\subsection{Investigation of ventilation methods when the entrance is closed}

\subsubsection{Investigation of issues of CASE3-4}

Figs. 18 to 20 show the results of the temperature, absolute humidity, and relative humidity calculations in the storeroom. The outside temperature is the daily average. When storerooms were opened in winter, it was difficult to reduce the relative humidity in the room to a target level. The reason seemed to be that humid outside air flows into the central room from the south side door when open. Therefore, in this case, the calculation was performed with the south side door closed. As a result, the storerooms were maintained in low humidity.

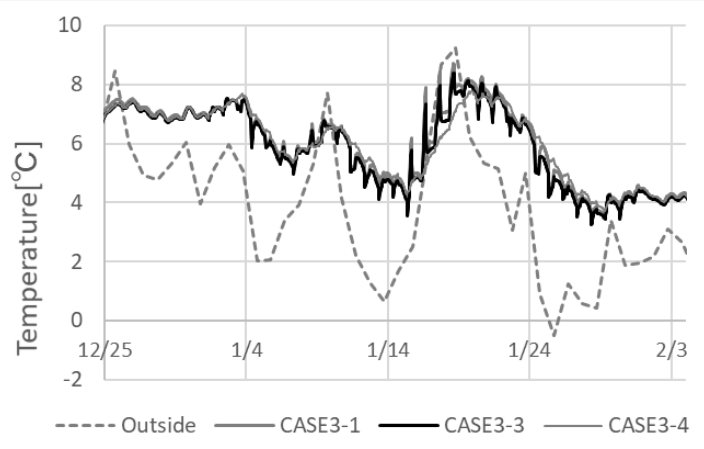

Fig. 18. Temperature of the central room during opening

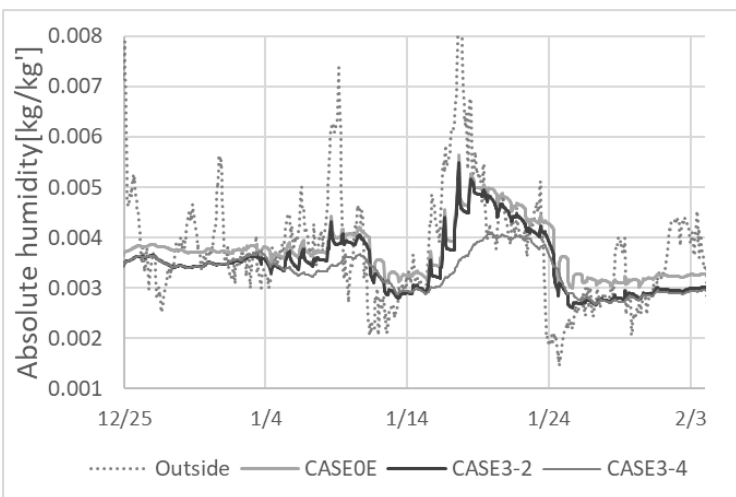

Fig. 19. Absolute humidity of the central room during opening

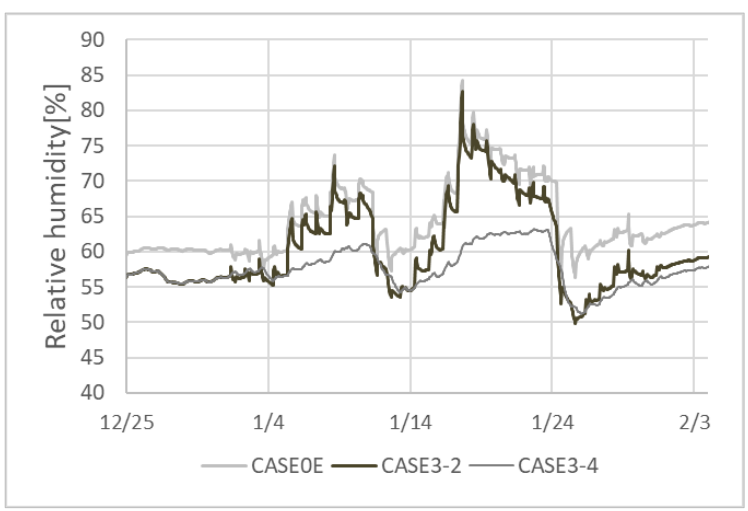

Fig. 20. Relative humidity of the central room during opening

\subsection{New calculation conditions for the ventilation method to dehumidify the attic space and the room independently}

When investigating the CASE3 series, we found the relative humidity of the room could be reduced, but the CASE3 method had some drawbacks: (1) ventilation depended on outside air humidity, (2) humid air was constantly entering the attic space, so the absorption ability of the attic space was reduced, and (3) the relative humidity of the rooms fluctuated greatly. To improve this situation, we referred to a method that uses the attic space for dehumidification. Areemit et al. proposed [12] separating the attic space and rooms during ventilation.

\subsubsection{Explanation of dehumidification method and calculation conditions}

The concept of using the attic space for dehumidification CASE4 is explained below. First, when the outside air is dry, the attic space and the storerooms are ventilated independently. During the day, the attic space becomes hot due to solar radiation, and the absolute humidity in the attic space rises due to moisture desorption from the interior material of the attic space. At this time, the outside air often has lower absolute humidity than the attic space, then by using outside air to ventilate the attic space, its interior materials can be dried. The outside air flowing into the attic is controlled by a fan, and by constantly drying, its dehumidifying capacity increases. When the humidity rises in the storeroom due to the generation of moisture, dehumidification is usually performed by ventilation with outside air. However, there is a case where the absolute humidity of the outside air is high due to rain. At this time, called emergency time, the dry air stored in the attic space is sent to the central room to maintain low humidity. In CASE4, it was assumed that outside air can be drawn from the east door into the attic using a duct. It was also assumed that an exhaust fan was attached to one of the windows in the central storeroom. Using this exhaust fan and the west room window, rooms would be ventilated independently from the attic space. The exhaust fan would operate when the absolute humidity in the central room became higher than outside, and the relative humidity in the central room became higher than 50\%. In addition, the openings in the ceiling of the central storeroom would be completely sealed, and the air in the central storeroom and the attic space exchanged only by the ceiling ventilation fan. In this calculation, the supply and exhaust volume of the fan was $648 \mathrm{~m}^{3}$. The operating conditions were that the ceiling fan in the attic and the ceiling fan were not operating and that the central storeroom's relative humidity was over $60 \%$. The operating conditions of each fan are summarized in Table 3. In Table 3, the thin characters indicate when the outside air is dryer than inside the room. On the other hand, bold characters indicate when the outside air's absolute humidity is higher than inside the room. 


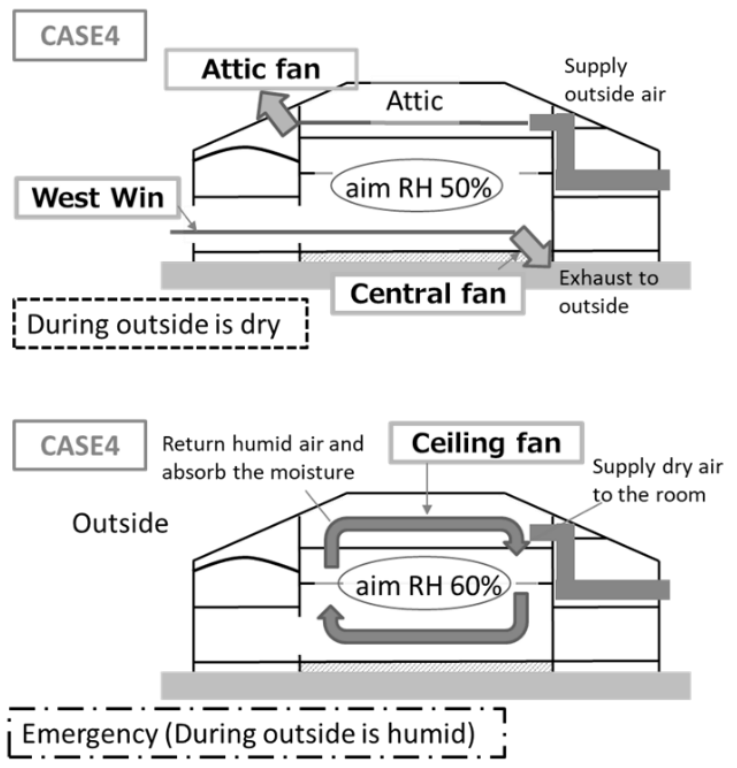

Fig. 21. Ventilation method in CASE4

Table 3. Condition of ventilation fan operating

\begin{tabular}{|l|c|c|c|}
\hline & \multicolumn{3}{|c|}{ central room's RH } \\
\hline FAN & $-50 \%$ & $50-60 \%$ & $60 \%-$ \\
\hline Central & OFF(OFF) & ON(OFF) & ON(OFF) \\
\hline Attic & ON(OFF) & ON(OFF) & ON(OFF) \\
\hline Ceiling & OFF(OFF) & OFF(OFF) & OFF(ON) \\
\hline
\end{tabular}

\subsubsection{The calculation result and discussion}

In the analysis of CASE4, the relative humidity in the room was set at $50-60 \%$. The calculation results in Figs.22-27 showed that the relative humidity in the storeroom was approximately within the control target range. To further narrow the range of relative humidity, it seemed necessary to identify an attic finishing material with a high moisture absorption/desorption performance to improve the moisture absorption performed in the attic space.

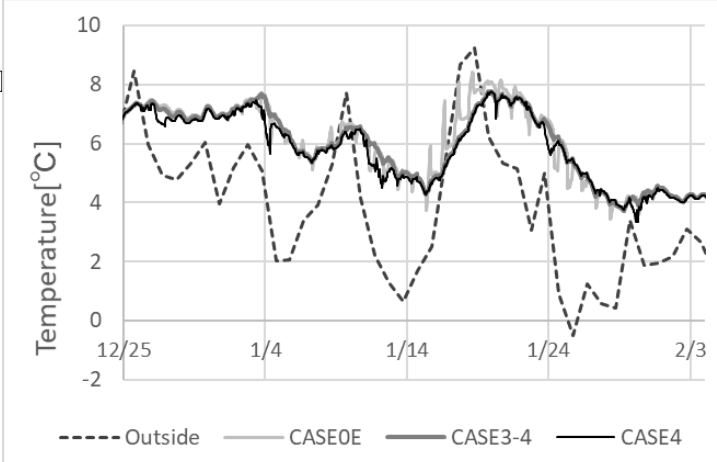

Fig. 22. Temperature of the central room during opening

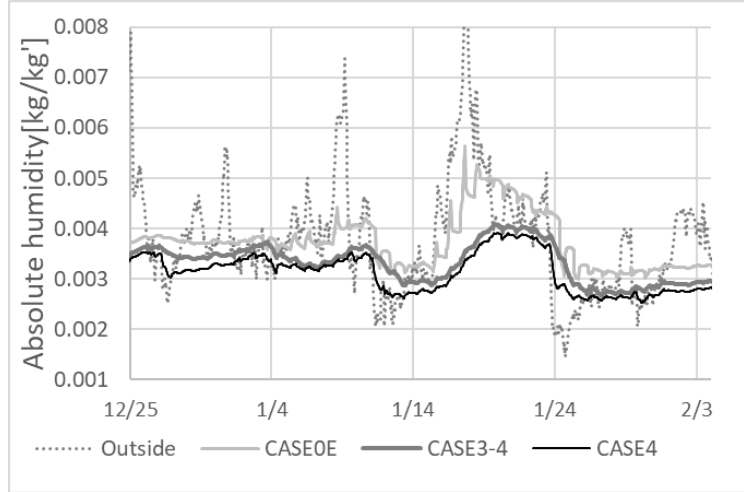

Fig. 23. Absolute humidity of the central room during opening

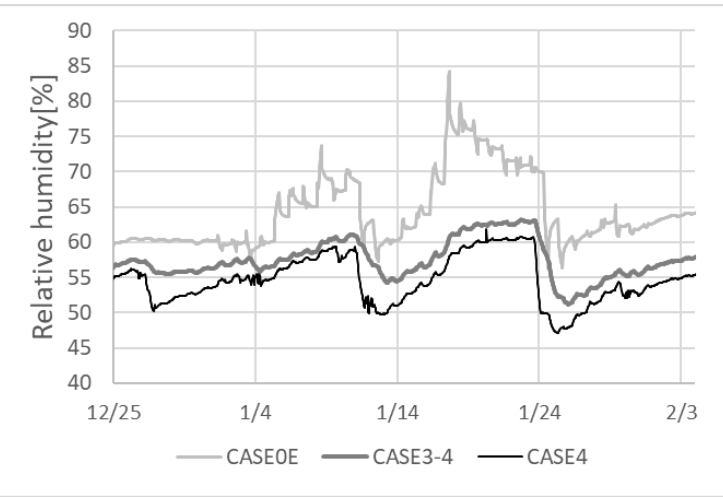

Fig. 24. Relative humidity of the central room during opening

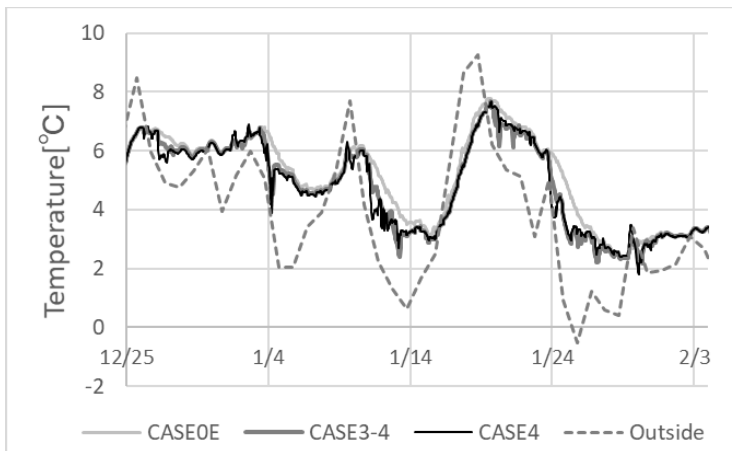

Fig. 25. Temperature of the west room during opening

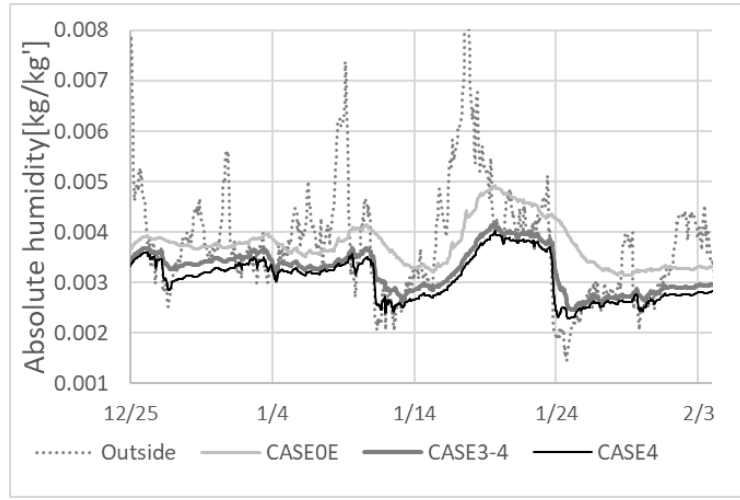

Fig. 26. Absolute humidity of the west room during opening 


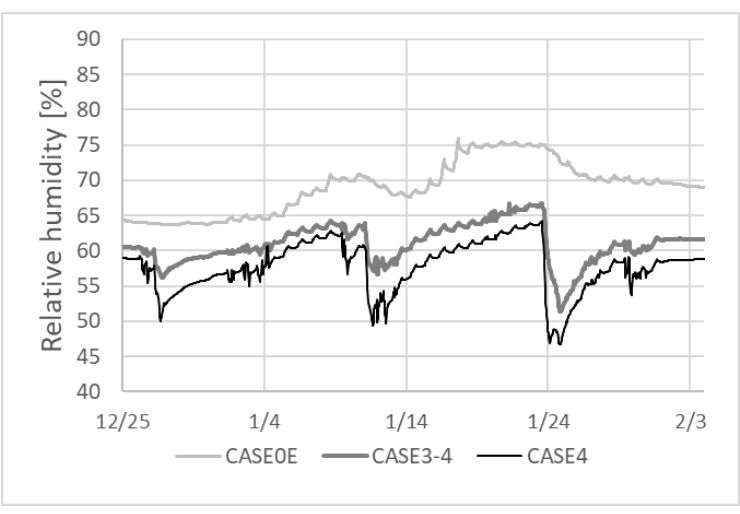

Fig. 27. Relative humidity of the west room during opening

\section{Conclusions}

In this study, we discussed and performed a numerical analysis of the hygrothermal environment of the treasure house at Horyu-ji Temple, which tends to be highly humid. We investigated various dehumidification case scenarios by proposing the operation of a ventilation fan in the attic space and on the ceiling and found the following.

1. When the absolute humidity in the attic space is higher than the outside air, moisture is extracted using the ventilation fan in the attic, and when the absolute humidity in the attic space is lower than that in the outside air/central storeroom, the air of the attic and storeroom are mixed using the ceiling fan. By extracting highly humid air and mixing what remains with dry air, the relative humidity in the storeroom can be reduced throughout the year.

2. When the storerooms are open to the public in winter, it is possible to reduce the relative humidity by ventilation using fans in the attic space and on the ceiling. However, when the absolute humidity outside is high, the outside air introduces moisture into the room from the entrance door. To prevent an increase in relative humidity, we have to concentrate on how visitors enter the room.

3. When controlling indoor humidity by taking in outside air, the relative humidity in the storerooms can be reduced on average. However, the fluctuation width is not small. It is necessary to identify an attic finishing material which has a high moisture absorption/desorption performance to improve moisture absorption in the attic space. If the moisture absorption capacity of the attic space increases, the relative humidity in the room could be stabilized further.

4. The influence of temperature and humidity fluctuations on the wall paintings is not yet clear. Sudden fluctuations in humidity can cause the paintings' surface to crack or flake off. Therefore, it is necessary to further investigate the murals' responses to fluctuations in temperature and humidity.

We received the cooperation of Horyuji, Asahi Shimbun and the Agency for Cultural Affairs of Japan for the survey.

\section{Reference}

1. Agency for Cultural Affairs, Committee on the Preservatin and Utilization of Mural Paintings at Horyu-ji Temple (19th), 7, (2016)

2. R. Fujihara, D. Ogura, C. Sano, S. Hokoi, C. Iba, Study on conservation and exhibition of burnt wall paintings in Main hall, in treasure house at Horyu-ji Temple- Investigation of environmental control method by numerical analysis with risk assessment of biological deterioration-, Architectural Institute of Japan Kinki Branch research report, 169-172 (2018)

3. Art and Cultural Affairs, Agency for Cultural Properties, Installation and Management Handbook for Cultural Property Conservation Facilities (2016)

4. A. Hukka, H.A. Viitanen, A mathematical model of mold growth on wooden material, Wood Science and Technology, 33, 475-485 (1999)

5. E. Takehiro, T. Wakui, K. Tomita, H. Meguro, Study on Insect Control and Control of Buildings (Part 1), Abstracts of Annual Meeting of Architectural Institute of Japan, D-2, 609-610 (2017)

6. New Architectural System Editorial Committee: New Architectural System 10 Environmental Physics, Humidity, Shokokusha (1984)

7. M. Matsumoto, Ho, Ogendon C.T., Afgan, N.H., Energy Conservation in Heating Cooling Ventilating Building; Heat Transfer Technique. Proc. of 1977 Int. Seminar of Heat and Mass Transfer, Dubrovnik. Hemisphere, 1-45, (1978)

8. T. Matsushita, Study on Prediction of Smoke Propagation for Evacuation Safety Evaluation in Fire, Ph.D thesis Kyoto University (1993)

9. T. Borostrom, C.-E. Hagentoft, M. Wessberg, Humidity Control Historic Buildings through Adaptive Ventilation-A Case Study, 9 $^{\text {th }}$ Nordic Symposium on Building Physics, Tampere (2011)

10. M. Wessberg, Design analysis of energy efficient indoor-climate control method for historic buildings, Ph.D thesis ,Czech Technical University in Prague (2019)

11. Japan Society for Air Conditioning and Sanitary Engineering: 12th Edition Handbook of Air Conditioning and Sanitary Engineering 3 Air Conditioning Equipment Design, Maruzen, 49-50 (1995)

12. N. Areemit, Y. Sakamoto, Numerical and experimental analysis of a passive roomdehumidifying system using the sorption property of a wooden attic space, Energy and Buildings, 39, 317327, (2007) 